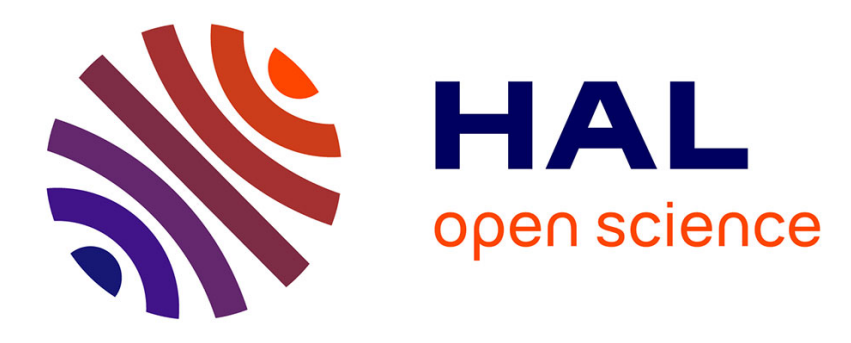

\title{
Models to detect scientific creativity: Why something simpler than Fréchet Metric Manifolds?
}

Francesco Dell'Isola

\section{To cite this version:}

Francesco Dell'Isola. Models to detect scientific creativity: Why something simpler than Fréchet Metric Manifolds?. Mathematics and Mechanics of Solids, 2015, 20 (9), pp.1146-1149. 10.1177/1081286514544077 . hal-01218899

\section{HAL Id: hal-01218899 \\ https://hal.science/hal-01218899}

Submitted on 21 Oct 2015

HAL is a multi-disciplinary open access archive for the deposit and dissemination of scientific research documents, whether they are published or not. The documents may come from teaching and research institutions in France or abroad, or from public or private research centers.
L'archive ouverte pluridisciplinaire HAL, est destinée au dépôt et à la diffusion de documents scientifiques de niveau recherche, publiés ou non, émanant des établissements d'enseignement et de recherche français ou étrangers, des laboratoires publics ou privés. 


\title{
Models to detect scientific creativity: Why something simpler than Fréchet Metric Manifolds?
}

\author{
Francesco dell'Isola \\ Dip. di Ingegneria Strutturale e Geotecnica Università di Roma La Sapienza, Italy; Int. \\ Research Center for Mathematics and Mechanics of Complex Systems MEMOCS Università \\ dell'Aquila, Italy
}

\begin{abstract}
We claim that the models needed to describe scientific creativity (and, in particular, suitable to effectively detect it) have to be very sophisticated. Indeed, the process of creating original and predictive scientific theories is manifestly the most complex ever investigated by the human mind (There are also some paradoxical aspects in the action of a mind that is investigating its own way of functioning, but we are confident that it will be possible to avoid them). In mathematical physics one of the most complex state space structures is given by Fréchet Metric Manifolds. We conjecture that they will be needed to model the state of complexity of the mind of a scientist (However, we will not be surprised if an even more complex structure could be needed). The obtained models have a very important application: they are essential to design and rule the selection process that assigns a university chair (or a research grant). Recently some algorithms have been introduced to calculate some bibliometric indices. We claim that it is not reasonable to use them to evaluate the scientific quality of researchers, chair or grant holders, departments or whole universities. Instead, the only presently viable process must involve carefully designed procedures, similar to those used for forming juries. These procedures must be enforced to rule the formation and functioning of ad hoc peer committees entrusted to evaluate academic institutions and nominate professors, chairs or research grant holders. Bibliometrics and Scientometrics are too young as disciplines and therefore it is not possible yet, by means of the theoretical insight gained thanks to them, to design a more effective evaluation process. Only when game and artificial intelligence theories become sufficiently advanced will it become possible to efficiently replace selection peers committees (i.e. academic juries).
\end{abstract}

\section{Keywords}

Scientific creativity, citations, academic juries

\section{The overwhelming complexity of the process of scientific creation and the oversimplified present efforts for describing it}

The Hellenistic States seem to have been the first ones (see Russo [1]) that organized public institutions where scientists were supported to produce original research, teach science to young generations and actively participate in the economical, technological and social progress of their societies.

Of course nearly immediately it became clear that the modality with which a chair (or a research grant) is assigned has long lasting and important effects. These effects determine the capability to evolve and progress those human societies that finance the work of scientists and scholars. Frederich II

Corresponding author:

Francesco dell'Isola, Università di Roma "La Sapienza", Via Eudossiana 18, Roma, 00184, Italy.

Email: fdellisola@gmail.com 
Hohenstaufen ${ }^{1}$ was aware of this truth and therefore entrusted his better jurist (Pier della Vigna) to formulate the laws ruling the Studium Neapolitanum, that is, the first modern State University [2,3]. Based on some considerations that cannot be completely presented in a limited space and that therefore are further developed by dell'Isola [4], ${ }^{2}$ we claim that the models needed to describe all phenomena related to scientific creativity (and, in particular, suitable to detect effectively its manifold manifestations) have to be, in fact, very sophisticated. This is to be expected, as the process of creating original and predictive scientific theories is manifestly the most complex ever investigated by the human mind. Moreover, it has always been suspected that when a rational mind starts to investigate its own functioning processes some paradoxical phenomena could arise, making vain the whole effort of self-analysis. One should expect that correspondingly complex models must be used to model human minds and to compare the efficiency of two or more human minds and eventually to establish which one is most suitable, for example for a occupying a given tenured position. In mathematical physics one of the most complex state space structures that is used is given by Fréchet Metric Manifolds. We conjecture that in order to establish a metric (in the sense of topology) in the set of the minds of all active scientists no simpler concept can be used. We could use for the imagined Fréchet Manifold the following name: Manifold of Human Intelligence. We go further to conjecture that a given position profile could be characterized by means of a point (or a compact subset) of the Manifold of Human Intelligence, and that the system in charge of the selection process could be asked to find the candidate that minimizes his distance from such a "target" set. For sure such a process needs the development of a very deep and complex theory and the design of very advanced artificial intelligence systems. ${ }^{3}$ This complexity seems to have been forgotten as in recent decades, instead of reasonably complex mathematical objects, it has been proposed to describe creativity, originality and inventiveness by means of the simplest mathematical objects that are available for modelling phenomena: natural numbers. Indeed, more and more often the different candidates for any position or research grant are evaluated and compared by means of so-called bibliometric indices. We claim that bibliometric indices cannot be used at all to evaluate the scientific quality of researchers, chair or grant holders; indeed, they are not a reliable measure of the independence and originality of the minds of the scientists with which they are associated. At most bibliometric indices are a measure of the social skills and popularity of the single researcher or of the managers of an academic institution. Moreover, the software programs used for calculating bibliometric indices are affected by some evident flaws. In particular, they are not able to handle family names, including apostrophes: the damage inflicted to individuals having this kind of family names is enormous and may also infringe the fundamental principle established by the International Covenant on Civil and Political Rights [5] about the right of having a name.

\section{The range of applicability of democratic vote and its limited applicability in some decision processes}

In the first forms of democracy (Athens and the Republican Rome), the delicate decision related to the guiltiness or innocence sentencing in criminal processes was entrusted to relatively large popular bodies. In Athens the average size of a jury was 501 members, while in the Republican period in Rome a jury constituted between 30 and 70 members, very often chosen by lot. It has been verified that such large bodies cannot too often arrive at a fair decision. Indeed, the populistic and political dynamics that arise inside them and the limited time in which they must arrive at a decision both represent unsurmountable limits. In the Anglo-Saxon juridic system peer juries constituted by 12 or at most 15 members were introduced, ${ }^{4}$ with a composition ruled by laws that assure the "distance" between the jurors and all persons involved in the criminal process. The formation of a jury is often done through a selection by lot. Experience has shown that, in this way, the optimal decision system for assuring both fair judgements and democratic control of judiciary (or selecting) system is obtained. ${ }^{5}$ The jury must be large enough to prevent the affirmation of strong personalities and small enough to prevent the onset of populistic group dynamics. Moreover, for small committees it is possible to impose a procedure that lasts a sufficiently long period of time to ponder carefully the decisions before passing to the final majority verdict. We claim that choosing professors and grant holders or evaluating single scientists or academic institutions by means of bibliometric indices is equivalent to entrusting large popular bodies for the selection 
or evaluation procedures. This choice is inducing very dangerous degenerations, allowing for frauds and, in general, producing a decrease of the quality of academic bodies. Those who support the use of bibliometric indices (because they believe that, in this way, the abuses occurred in the decision of peer selecting committees can be avoided) must admit that the limits of the system based on "academic jury" formation cannot be reduced by replacing these juries with an algorithm based on bibliometrics indices. Indeed, bibliometric indices can (and are) manipulated by the coordinated actions of networks of the authors of scientific papers. Moreover, when using bibliometric indices it is nearly impossible to establish who selected a certain chair or grant holder. Instead, the appointment of a jury is always clearly establishing a public link between the decision maker and the selected person.

\section{To stop frauds in the decision process based on the appointment of academic juries is simpler than avoiding frauds in the citation mechanisms}

Indeed, it is possible to conceive and carefully design procedures, similar to those used for forming juries for criminal processes, to rule the formation and functioning of the peer committees entrusted to nominate professors, chair and research grants holders. On the other hand, although they are based on some deep and useful intuitions, Bibliometrics and Scientometrics are yet too young as disciplines; therefore, it is not possible yet, by means of the theoretical insight gained thanks to them, to design new procedures that are better and more effective than those based on academic juries. In order to replace the old, well-established and most efficient procedures it will be necessary to wait for the development of Turing machines that are able to pass a more complex version of the Turing test. In this, a group of human scientists must try to discern between one of their colleagues and a suitably designed expert Turing machine. Such a machine, once having passed such an enhanced Turing test (and under the control of a strong and stable "fairness" and "honesty" algorithm) will be able (possibly) to replace human juries. This will happen only when game and artificial intelligence theories reach such a level of development that a decision-making process based on their results will become more reliable than that based on randomly chosen sets of well-qualified humans.

The thesis which is put forward here is as follows:

\section{bibliometric indices cannot replace peers evaluation and selection committees}

The development of the web and the increase of computing machine speed supplies to scientists a further powerful tool: the virtual total availability of all published papers and textbooks and the possibility of consulting them in real time from every internet connected computing machine. The dream of the founders of the Library of Alexandria seems close to be fully realized. By using suitable software and appropriate search keywords every knowledge already acquired by science will be soon available under the fingertips of every scientist (if the prices of commercial publishers are not be too high). Undoubtedly, this possibility will contribute to an acceleration in the accumulation and organization of human knowledge. However, as with every tool conceived by the human mind, the uses of such a powerful tool are not all leading only to positive and desirable effects. Indeed, the recent possibility of easily calculating any kind of bibliometric index induced some serious distortions in the structure of academic institutions. These distortions can have very serious consequences in the capability of the future generations of scientists to produce original, creative and effective research. Indeed, the more and more popular tendency to base evaluation of scientific papers, scientists, groups of scientists and whole universities on the calculation of some bibliometric indices is transforming scientific research into a social game whose aim is simply to get more citations. The enormous increase of published papers, citation counting and automatic evaluation of scientific quality tools is distracting too many creative scientists from the formulation of carefully pondered theories and is, instead, inducing them to indulge in the dangerous philosophy whose motto is "publish or perish". The claim of this editorial is that the evaluation the scientific quality of researchers, professors and scientific projects cannot be obtained by means of the mere calculation of some simple natural numbers. Instead, as done up to few years ago since the foundation of the first universities, this evaluation process must be entrusted to a peer committee, that is, an academic jury. As the process of selecting a new professor (or of assigning a munificent research grant) is very expensive for the whole society it must be carefully controlled; therefore, it should be ruled in a similar way as a 
criminal process aimed to establish the guilt or innocence of a citizen. Selecting peer committees (academic juries) must be, however, formed following carefully designed legal rules and constituted exactly as it is done for juries. The interested reader is referred to detailed discussion of this thesis in dell'Isola [4], Robinson [6], Stergiou and Tsikliras [7], Stergiou and Lessenich [8] and Taylor et al. [9].

\section{Funding}

This research received no specific grant from any funding agency in the public, commercial or not-for-profit sectors.

\section{Conflict of interest statement}

None declared.

\section{Notes}

1. He was the heir of the Kingdom of Sicily and Sacred Roman Emperor, one of the most enlightened Sovereigns of Italian history and the grandson of Frederich Barbarossa (Red-Beard in Italian), that is, the first Emperor who protected the freedom of the newly established Universitas Bononiensis (Authentica Habita or Privilegium Scholasticum Friderici I).

2. Where the ancient form of Juvenal-style satire is used to reinforce the rational arguments presented here and, in more detail, there. In other words, the cited paper tries to redress degenerated customs by ridiculing them (as suggested by the motto: Castigat Ridendo Mores).

3. Such an enormous technological progress could be closer than we can now imagine: consider that recently an intelligent machine could get a relatively high score in a Turing test (greater than one third).

4. It is suggested to recall: (i) The Magna Charta Libertatum, where the principle of peer judgement was established, was given in 1215; (ii) The Studium Neapolitanum was founded in 1224; and (iii) Pier Della Vigna was sent as ambassador in England in 1235 .

5. Recently, in Italy and for a short period, the university selecting committees were formed using a choice by lot among all professors working in the whole country: the results of the action of the so formed committees were so surprisingly of high quality that the Italian Parliament changed the law immediately.

\section{References}

[1] Russo, L. The forgotten revolution how science was born in 300 BC and why it had to be reborn. Berlin: Springer, 2004.

[2] AA.VV. Enciclopedia Federiciana Ist. Naz. Encicl. Treccani: Studio di Napoli.

[3] Verger, J. Les universités au Moyen Age. Paris: Presses Universitaires de France, 1973.

[4] dell'Isola, F. A difficult problem for artificial intelligence: how to assess originality of scientific research and the dangers of apostrophes in family names, http://hal.archives-ouvertes.fr/index.php?halsid=ifta5vrtsjit7mpei46v0h6a94\&view_this_ doc $=$ hal-01002678\&version $=1$ (accessed 22 June 2014).

[5] UN General Assembly resolution 2200A (XXI) of 16 December 1966, http://www.ohchr.org/EN/ProfessionalInterest/ Pages/CCPR.aspx

[6] Robinson, D The mismeasure of higher education? The corrosive effect of university rankings. Ethics Sci Environ Polit 2014; 13: 65-71.

[7] Stergiou, KI, and Tsikliras, AC. Global university rankings uncovered: introduction. Ethics Sci Environ Polit 2014; 13: 59-64.

[8] Stergiou, KI, and Lessenich, S. On impact factors and university rankings: from birth to boycott. Ethics Sci Environ Polit 2014; 13: 101-111.

[9] Taylor, M, Perakakis, P, Trachana, V, et al. Rankings are the sorcerer's new apprentice. Ethics Sci Environ Polit 2014; 13: 73-99. 